\title{
An Overview of IODP Scientific Publications
}

\author{
by Emanuel Soeding, Dan Evans, Ann Klaus, Shin'ichi Kuramoto, \\ Hans Christian Larsen, and Angie Miller
}

\section{Development of IODP Reports and Publications}

A new series, the Proceedings of the Integrated Ocean Drilling Program, is continuing the legacy of scientific ocean drilling publications that began with the Initial Reports of the Deep Sea Drilling Project and the Proceedings of the Ocean Drilling Program. Together, these series document almost forty years of ocean drilling expeditions.

In 2004, the format of the Proceedings of the Integrated Ocean Drilling Program was defined based on input from the ocean drilling scientific community, the Integrated Ocean Drilling Program (IODP) Implementing Organizations, scientific publishers, and program management (IODP-MI). The IODP scientific publications structure comprises a report series, a Proceedings series, and the program journal Scientific Drilling (Fig. 1). The new IODP publication structure is, except for the journal, exclusively electronic and offers easy Web access (http://www.iodp.org/scientificpublications/). Another important element is the program

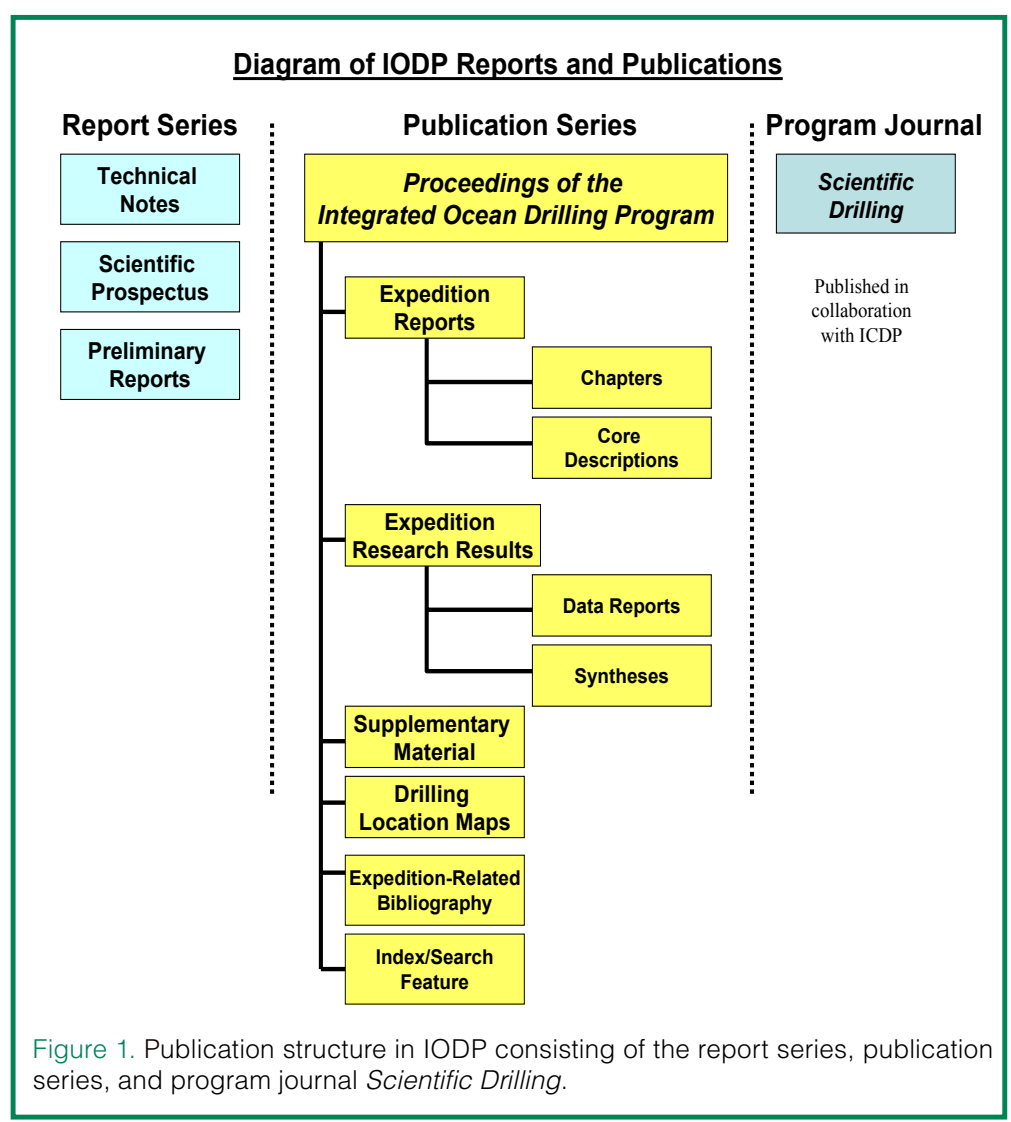

decision to pursue publication of scientific papers related to post-expedition research in the open, peer-reviewed literature.

\section{IODP Reports}

The IODP report series comprises IODP Scientific Prospectus, IODP Preliminary Report, and IODP Technical Notes. The Scientific Prospectus outlines the expedition plan and is published no later than two months before an expedition. The Preliminary Report summarizes the expedition technical operations and scientific results and compares the expedition achievements to the expedition goals outlined in the Scientific Prospectus. The Preliminary Report is prepared for publication within two months after the conclusion of an expedition. Technical Notes documents program-related scientific and engineering operational documentation and is published on an as-needed basis.

\section{IODP Proceedings}

The Proceedings of the Integrated Ocean Drilling Program is a serial publication that contains a detailed summary of expedition technical operations and scientific results and related peer-reviewed data reports and synthesis papers that cover postexpedition research. A single Proceedings volume will be published for each IODP expedition or drilling project (a series of related expeditions). Each volume is divided into two main sections- "Expedition Reports" and "Expedition Research Results." The Expedition Reports section contains a record of the expedition objectives, a thorough summary of the scientific and engineering results, and core description data and is published on the Web in HTML and PDF formats and on DVD (Fig. 2) at the end of the sample and data moratorium period. The Expedition Research Results section will contain peer-reviewed data reports and synthesis papers based on post-expedition research. In a change from the Ocean Drilling Program (ODP) and Deep Sea Drilling Project (DSDP), all other scientific papers documenting IODP post-expedition research results will be published in peer-reviewed English language journals. To ensure that the IODP continues to obtain a compendium of expedition-related work, each Proceedings volume also includes a bibliography of 


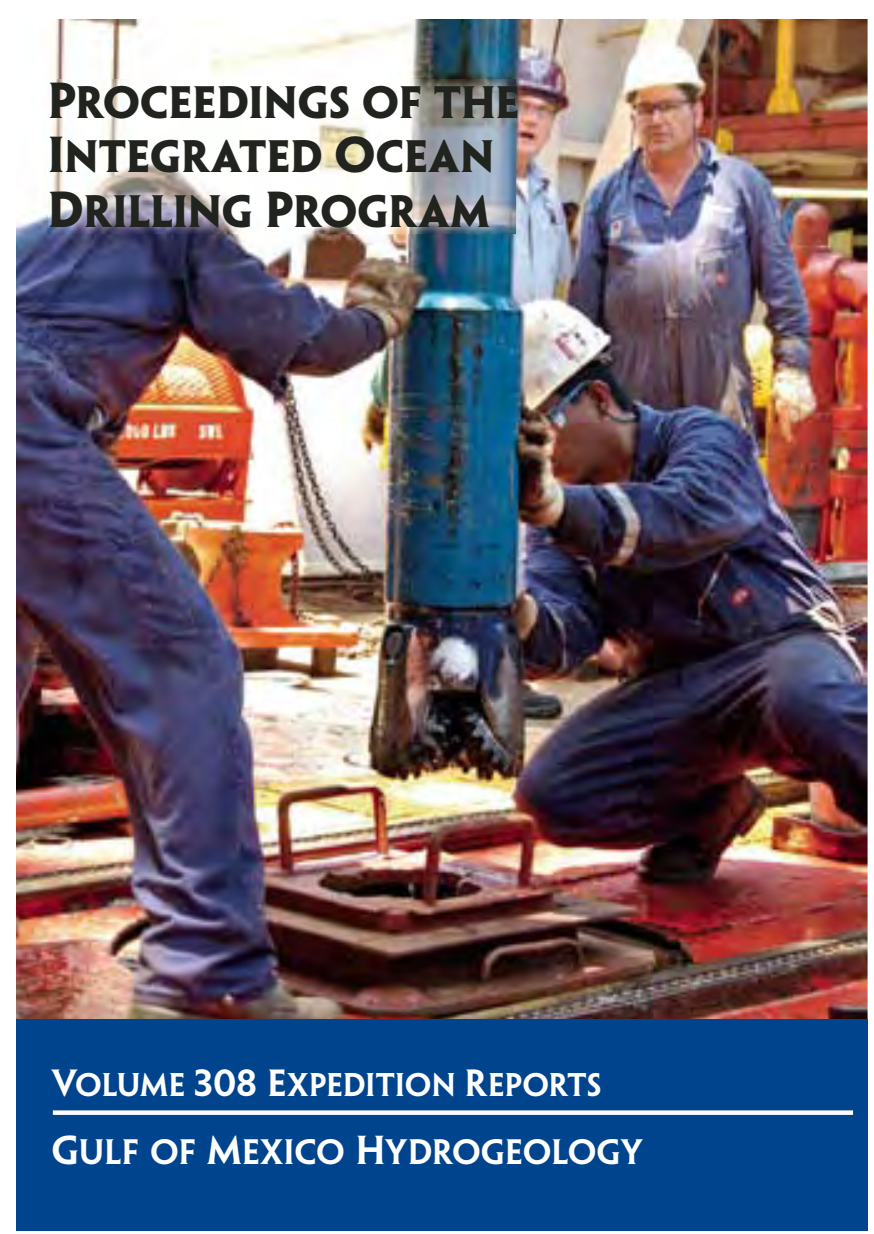

Figure 2. Cover of Volume 308 DVD of Proceedings of the Integrated Ocean Drilling Program published in 2006.

references from expedition-related publications. Readers can also link to abstracts and papers that are published electronically in open-access journals. Maps of expedition drilling sites and supplemental data in proprietary formats other than PDF and ASCII are also included in the Proceedings. Each volume will be completed three years after the corresponding sample and data moratorium.

\section{Scientific Drilling}

The journal Scientific Drilling is published by IODP jointly with the International Continental Scientific Drilling Program (ICDP) to broaden the impact of IODP scientific results, forge a partnership with the ICDP, and establish a common source of information for all scientific drilling. The journal accepts brief scientific contributions on any aspect of scientific drilling-land, sea, lake, or ice- including borehole instrumentation and long-term observatories. A key element of the journal is brief summary articles or progress reports from all IODP and ICDP expeditions and projects. Scientific Drilling is issued in print and online in PDF format twice a year, with publications scheduled in March and September.

\section{Developments}

IODP scientific publications incorporate Web-based information technology that increases reader access and allows a stronger integration of text-based publications and data objects in distributed data repositories. The IODP has joined CrossRef to register digital object identifiers (DOIs) for all IODP scientific reports and publications. The DOI system improves accessibility to scientific publications and provides a method for member publishers to cite and link to each others' online publications. To further improve access to IODP-related research, The IODP will work with publishers to provide open access to publications that contain results from IODP data. The program is also taking steps to further integrate publications with program-generated data as well as data from other related programs through the Scientific Earth Drilling Information System (SEDIS). Proposed enhancements in SEDIS Phase 2 include advanced search tools for both text and data (Miville et al., 2006). As the IODP moves forward implementing new techonology, the ODP reaches back to secure the legacy of multiple decades of scientific ocean drilling through an exciting initiative to digitize the printed Initial Reports of the Deep Sea Drilling Project series and the early volumes of the Proceedings of the Ocean Drilling Program series. These volumes will be available online in PDF format in 2007-2008 with textsearching capability. For further information please contact: publications@iodp-mi-sapporo.org.

\section{Reference}

Miville, B., Soeding, E., and Larsen, H.C., 2006. Data Management in the IODP, Scientific Drilling, March 2006, No.2, p. 48-49.

\section{Authors}

Emanuel Soeding, IODP-MI, CRIS Building, Rm. 05-101, Hokkaido University, N21 W10 Kita-ku, Sapporo, 001-0021 Japan, e-mail: publications@iodp-mi-sapporo.org.

Dan Evans, ECORD Science Operator, British Geological Survey, Marine Operations and Engineering, Murchison House, West Mains Road, Edinburgh EH9 3LA, Scotland, U.K.

Ann Klaus, Integrated Ocean Drilling Program U.S. Implementing Organization, Texas A\&M University, 1000 Discovery Drive, College Station, Texas 77845-9547, U.S.A.

Shin'ichi Kuramoto, Center for Deep Earth Exploration, Japan Agency for Marine-Earth Science and Technology, 215 Natsushima-cho, Yokosuka, 237-0061 Japan.

Hans Christian Larsen, IODP-MI, CRIS Building, Rm. 05101, Hokkaido University, N21 W10 Kita-ku, Sapporo, 0010021 Japan.

Angie Miller, Integrated Ocean Drilling Program U.S. Implementing Organization, Texas A\&M University, 1000 Discovery Drive, College Station, Texas 77845-9547, U.S.A. 